\title{
In Memoriam: A Celebration of Joachim Nagel's Life
}

\author{
Luis Kun ${ }^{1}$
}

Published online: 25 April 2018

(C) IUPESM and Springer-Verlag GmbH Germany, part of Springer Nature 2018

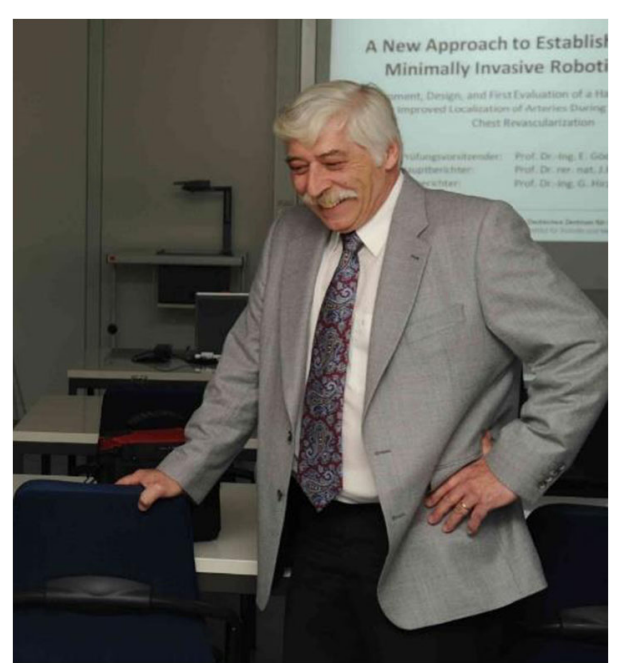

Fig. 1 Joachim Nagel

"Losing a colleague unexpectedly, at any time in your life, is a very sad and confusing time. Yet it is a reality check that combines the good times spent together with the sadness of the news and a reflection regarding our own mortality. When this person is, in addition, a good friend, the task of writing a eulogy becomes more difficult because your heart and sentiments interfere deeply with the logic of writing a piece in this precise moment where all you want is to focus on the departed one and find the right words to honor him" [1] (Fig. 1).

Luis Kun

hcii@aol.com

1 W. Perry, Center for Hemispheric Defense Studies at National Defense University (retired), Washington, DC, USA

\section{The genesis of this Journal -}

"In June 2009 my colleague Robert Mathews and I put together an Interoperability Summit entitled 'Healthcare Reform or Healthcare Transformation' https://www. hawaii.edu/csati/Summit.html at the U.S. National Academy of Sciences/Engineering in Washington DC. About 30 professional organizations (i.e., ICMCC, IFMBE, SSIT, AIMBE, EMBS, Computer Society, etc.) and 23 different U.S. Federal Agencies / Departments attended as well as many of you" [2].

In this meeting, Joachim Nagel as President of the IUPESM was a member of the Summit's Advisory Council. After a first day of presentations made by representatives of 23 different agencies / departments, a series of discussions ensued with representatives of 30 different professional organizations. With the purposes of improving quality of life and diminishing the costs of healthcare, this meeting discussed and conveyed conclusions of the severe need to encourage, organize and institute healthcare reforms and practices to the President of the United States, of the severe need to encourage, organize and institute healthcare reforms and practices from the perspective of making prominent, a critical focus on wellness, in a very wholistic manner, and through the eyes of multi-disciplines and inter-disciplines.

In the opinion of this author, the concepts, challenges and potentiality of solutions, discussed at that meeting, opened in Joachim's mind, the possibility of creating a Journal that would aim to facilitate the transmission of complimentary messages - to the world.

For a year following this meeting, I spoke with Joachim and we discussed his intention of creating a Journal that would look at healthcare in the world from such a wholistic perspective. As I was preparing to lecture at the U.S. European Command (EUCOM) in Stuttgart, Germany, during the last week of June 2010, I called 


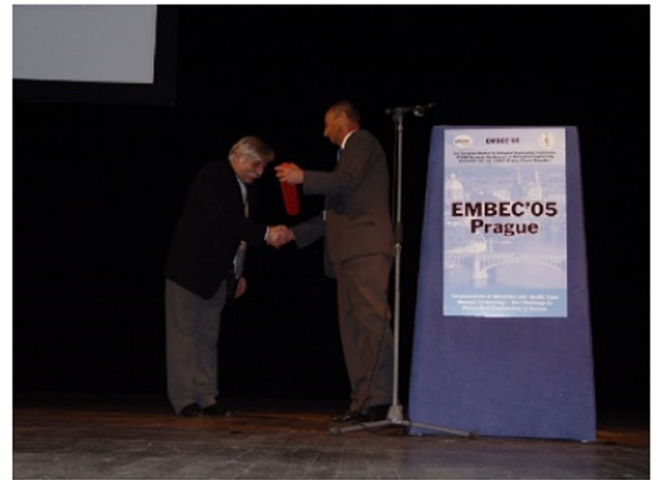

Fig. 2 Receiving the Honorary Membership of the Czech Society for Biomedical Engineering during PRAGUE EMBEC 2005

Joachim and requested that he, too, present a lecture within my course, and we discussed meeting the prior week to explore the creation and launch of the new Journal. Five people were going to participate in that discussion: Monika and Joachim Nagel, Christoph Baumann (representing Springer), Lodewijk Bos and myself. In late June, 2010 we met. During the next following ten days a wonderful relationship developed between all of us. Joachim was installed as the Founding Editor, and Lodewijk Bos and I were appointed as Co-Editors in Chief for the International Journal of Health and Technology. That weekend, we spent time defining precisely what the goals and objectives for the new Journal would be. These conversations forged and helped define what would become our first Editorial: "Just another journal? No, a different one!" [3].

\section{My life circle}

It is interesting to note that in that "transformational" 2009 Summit at the National Academies, the Summit's Advisory Council included Lodewijk Bos (as President of the International Council on Medical \& Care Compunetics

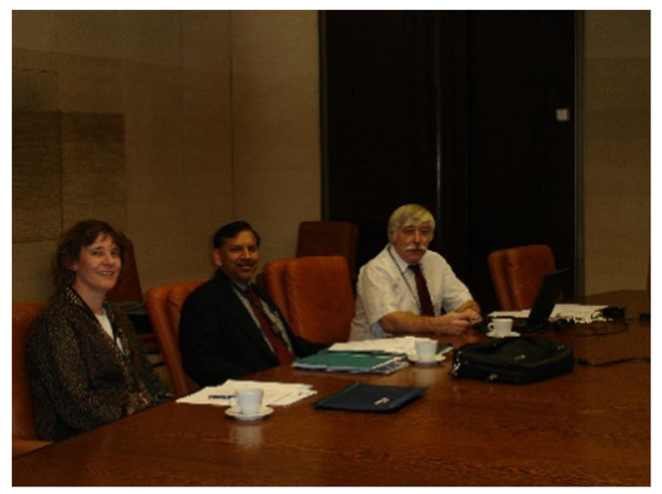

Fig. 3 Working with colleagues

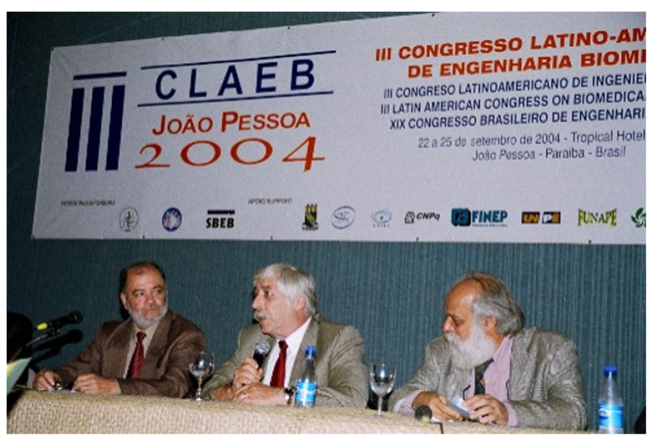

Fig. 4 Opening CLAEB 2004

(ICMCC)). The Scientific \& Technical Advisory Board led by Robert Mathews included Herbert Voigt (as President Elect of IFMBE). Both Bos and Voigt, are no longer with us, but were for many years - part of my professional and personal circles.

When a colleague or a friend dies, those that knew the individual, often experience a mixture of challenging emotions. If it was unexpected, the emotional pain can be overwhelming to some. Yet, while one/we carry that heavy weight in our hearts, many thoughts of wonderful moments, conversations and shared experiences invade our minds concurrently. Similarly, stark reminders of our own mortality at such times can push those of us that remain to use words like, "I love you" and "thank you" more often, with those that are still around... just in case.

To write something to honor those that have left our midst may seem easy, but it turns out to be difficult once you are alone and in front of an empty screen or piece of paper. Some tend to review the $\mathrm{CV}$ of the departed, making chronological notes of the person's accomplishments. In fact, by definition, an obituary is a notice of a person's death usually with a short biographical account. Similarly, a eulogy is a high praise, or a

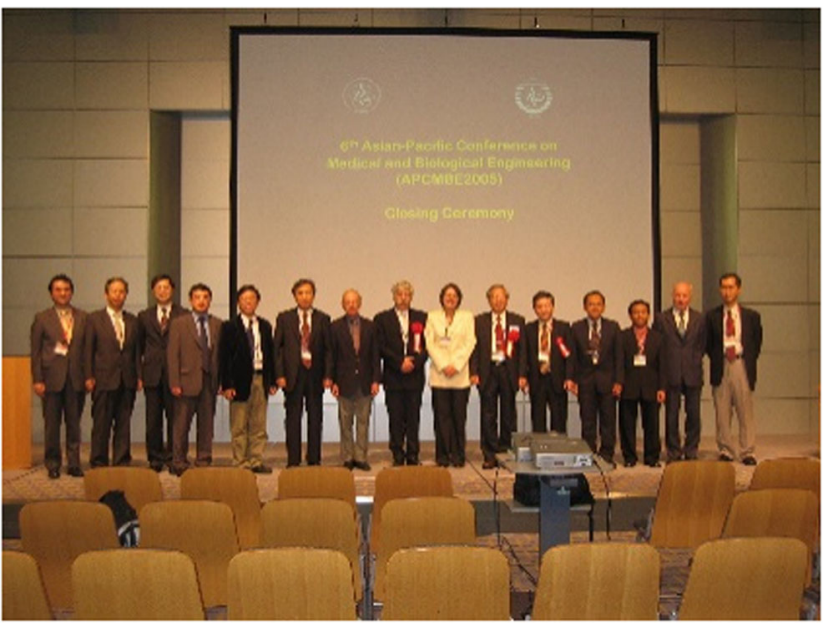

Fig. 5 Closing APCMBE 2005 


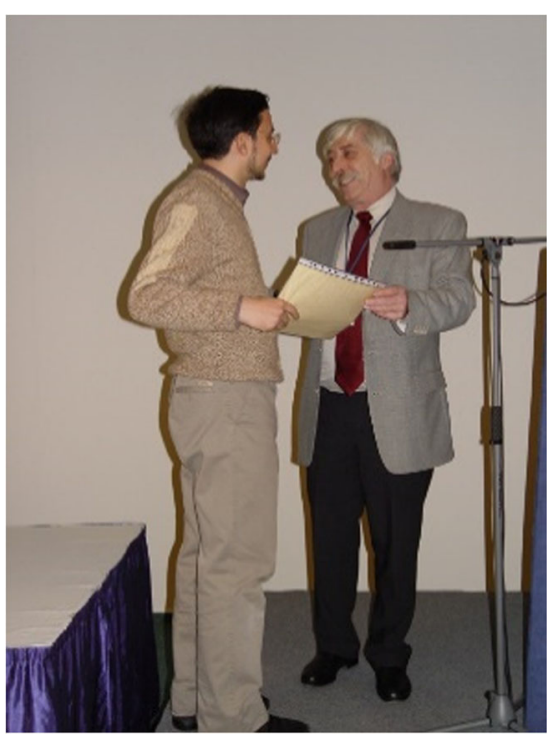

Fig. 6 Closing YIC Award

commendatory oration or a writing especially - to honor of one deceased.

While these accounts serve future generations mainly, to learn and understand the scope of intellectual contributions of individuals in their given fields of expertise, the challenge is: very little is often said about the individual himself ... who the person really was. Recalling special collegial moments in particular can also be challenging. I have re-visited with colleagues and friends, certain special moments we have shared in the past. And it never ceases to amaze me how, in such a group, individuals remember a specific event quite differently.

In the 80 s, while Joachim was working as a professor of biomedical engineering at the University of Miami in Florida, he and I spoke occasionally. At the time, I was working for IBM, and used to travel to Boca Raton, where IBM was developing their Personal Computer. As time went by, Joachim was going to organize the 1989 Engineering Medical and

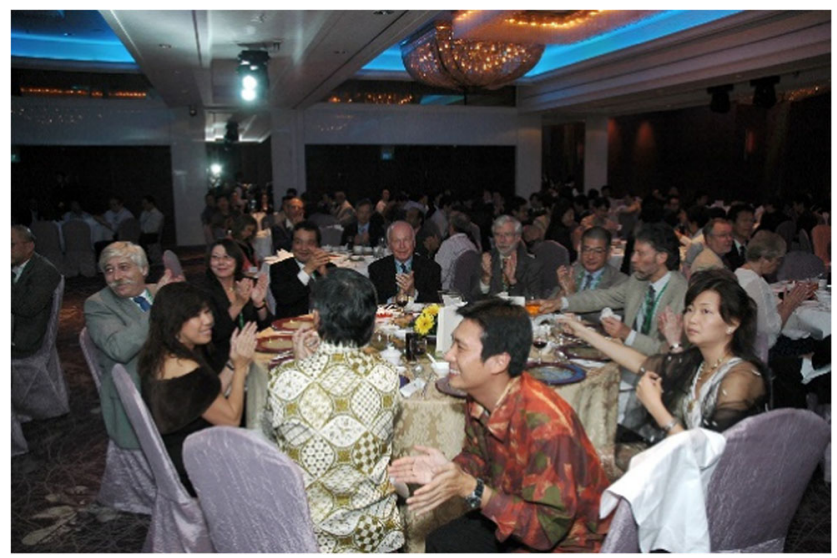

Fig. 7 Gala dinner during Singapore event

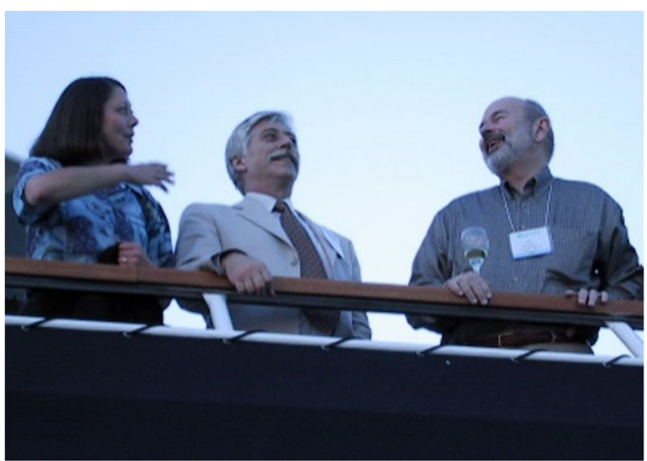

Fig. 8 Enjoying friends / colleagues

Biological Society (EMBS) Conference / annual meeting, and it was to be located in Orlando, Florida. I met him and his wife Monika during that meeting. Joachim was open minded and the Conference that he had organized was holding sessions/tracks that had never been tried before. For the same meeting, I coordinated with my colleague and friend Swamy Laxminarayan to organize a Special Session on Medical Imaging, bringing participants not only from academia, but from industry (i.e., Ralph Bernstein IBM Palo Alto Scientific Center, and Richard Robb, Mayo Clinic) and government (i.e. Mike Ackerman NLM/NIH). Although the special sessions were outstanding with standing room only, the most memorable times and connections within that meeting were presented at the spectacular reception party organized by the Nagels. A fantastic ensemble of parachutes covered the tables. Everything was achieved with a lot of good taste. A fantastic culinary display was much appreciated, and enjoyed by all the participants. As I recall them, the food, drinks and the social interactions, were outstanding... in fact, I had never seen such a display of generosity, great planning and excellent taste, in any of the prior EMBC meetings, or since.

Joachim and I established a great working relationship after that, and eventually, the Nagels returned to their motherland,

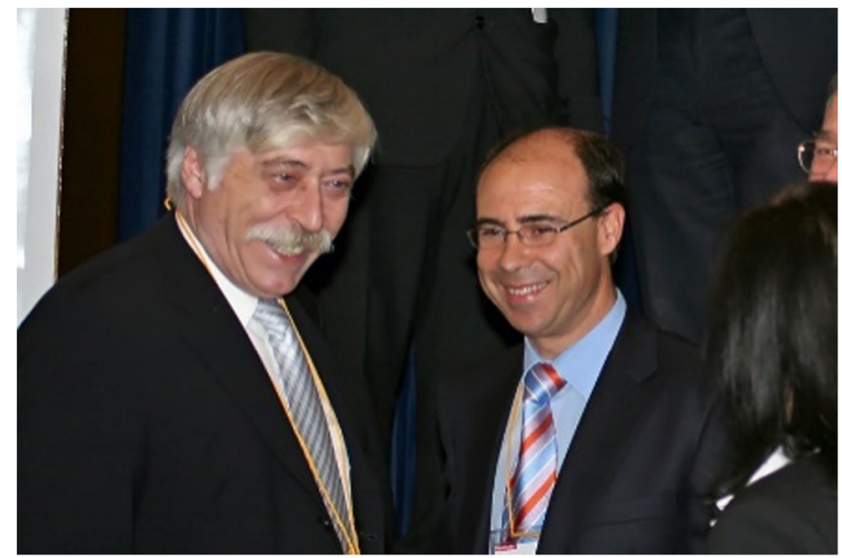

Fig. 9 Enjoying friends / colleagues 
Germany. Although we maintained some contact during the following decade, in the 90s, it wasn't until later, when I got to represent the American Institute of Medical and Biological Engineering (AIMBE) with the International Federation (IFMBE), that I became more involved in its activities, and again with Joachim. I was asked by Joachim to be part of the IFMBE Nominating Committee and afterwards I was elected to their Administrative Council during the World Congress in Munich in 2009.

Joachim Nagel was a brilliant scholar. A very intense and focused individual, who tried to understand the plight of others by confronting life's challenges upfront. In certain ways he was very transparent and perhaps rigid. But he took his time, to make what he thought were the correct and proper decisions. If Joachim was challenged with the right data or information, he had the open mind and the flexibility to accept changes.

Joachim was a very special and a wonderful man. With the help of certain pictures, I have tried to depict a person - who was not only an outstanding professional and a very hard worker, but an intellectually and spiritedly connected human being, that enjoyed his family, friends and life. To those that had the privilege of meeting him he left a testament of a life well lived.

Please note Fig. 2. The podium reads: EMBEC'05. The keynote was given in the same city (Prague) and location where the IUPESM World Congress will take place, and we will be honoring his life, on Thursday, June 7, 2018.

These pictures that follow, reflect how some of us and the public saw Joachim, working during IFMBE / IUPESM related meetings and conferences. They reflect his many contributions during opening keynotes, working with other members of the IFMBE / IUPESM family, providing awards to participants, sharing the podium with country organizers, and or enjoying a Congress dinner with other colleagues. They also reflect audiences from distinct geographical parts of the world,

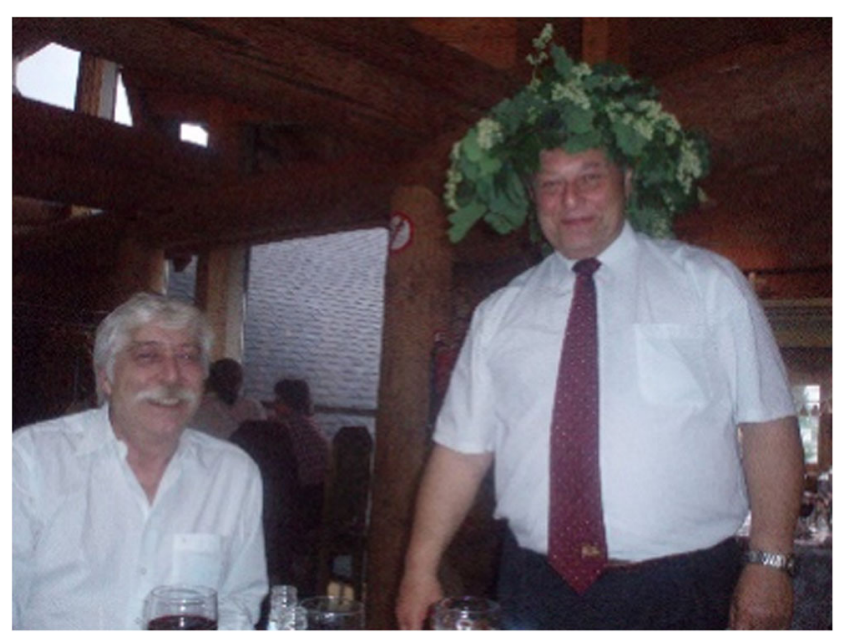

Fig. 10 Enjoying friends / colleagues

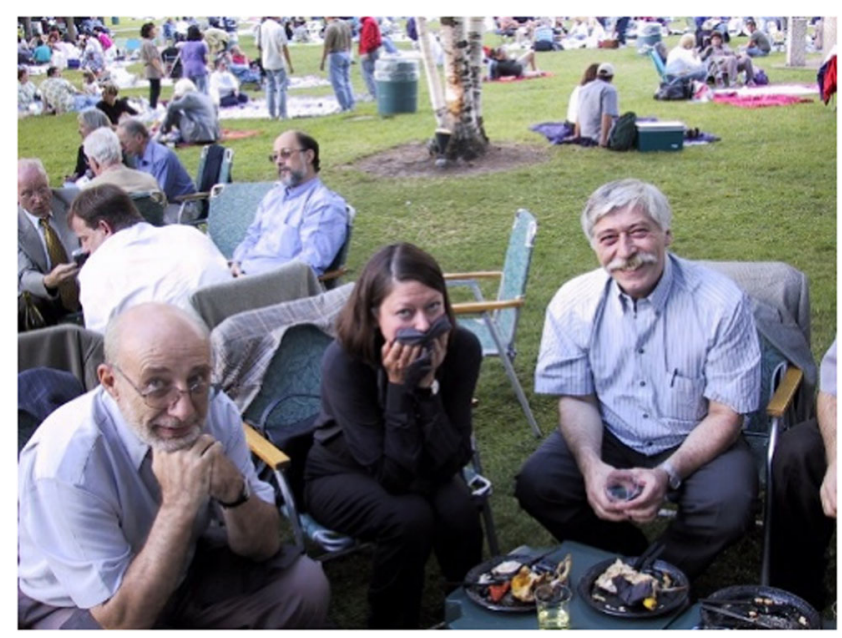

Fig. 11 Enjoying friends / colleagues

i.e. Brazil, Singapore, Prague, etc. While representing multicultural, multi-ethnicities, multi-religious, environments, Joachim always searched for the common interests of biomedical engineers and medical physicists from around the world.

Figures: 3, 4, 5, 6 and 7 show Joachim Nagel, working behind closed doors; sharing a panel in Brazil, CLAEB 2004; providing a young investigator award at a closing ceremony; and participating in a gala dinner during the Singapore meeting.

The following pictures reflect the "other side" of Joachim, and the way his friends and family will also remember him. A joyous and hard working soul Figs. 8, 9, 10, 11, and 12.

Thank you Joachim, for sharing your life with us. Your light will continue to illuminate and to guide those that had

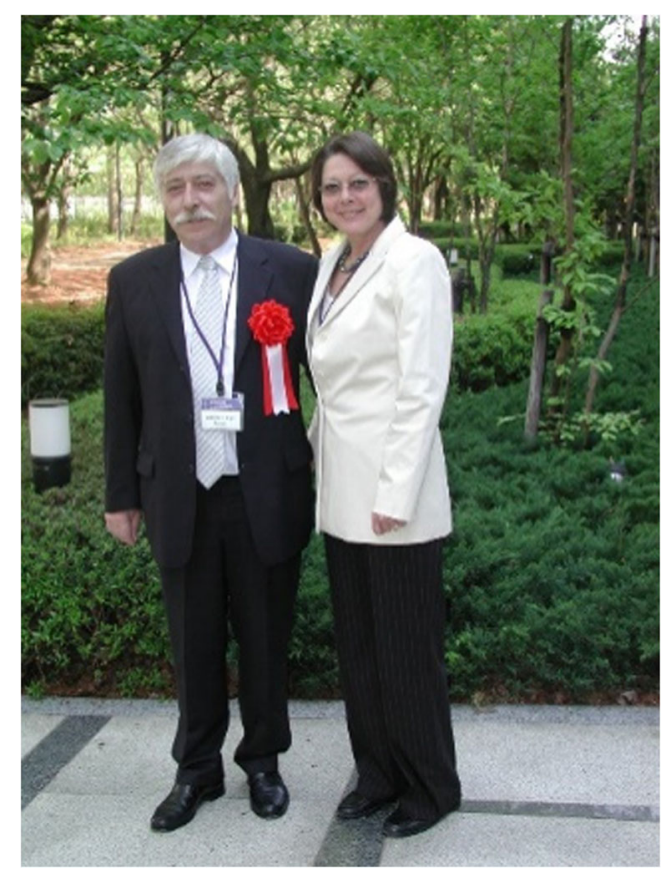

Fig. 12 Joachim and Monika Nagel 
the opportunity of meeting you, and those many in the future that will benefit from your ideas, and your legacy.

Rest in Peace, dear friend and colleague.

\section{Compliance with ethical standards}

Conflict of interest The authors declare that they have no conflict of interest.

\section{References}

1. Kun L. Health Technol. 2015;4:295. https://doi.org/10.1007/s12553015-0101-7.

2. Kun L. Health Technol. 2015;4:297. https://doi.org/10.1007/s12553015-0101-7.

3. Bos L, Kun L. Just another journal? No, a different one!. Health Technol. 2011;1:1-4. 